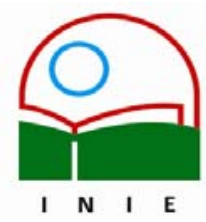

Universidad de Costa Rica

Facultad de Educación

Instituto de Investigación en Educación

ACTUALIDADES INVESTIGATIVAS EN EDUCACION

\title{
MATERNALIZACIÓN DE LA ENSEÑANZA BÁSICA EN EL AULA
}

\section{Viriam Leiva Díaz ${ }^{1}$}

Resumen: El presente es un estudio cualitativo, cuyo objetivo fue analizar la maternalización del rol docente en el aula. Para la recolección y el análisis de los datos se utilizó como método la fenomenología hermenéutica y la perspectiva de género. Se definieron sujetos de análisis, el aula, las docentes, las estudiantes y los estudiantes.

Se evidenció que en su labor las maestras asumen implícita, y explícitamente, una prolongación del seno materno, coincidiendo la percepción afectiva de las niñas y los niños hacia su maestra con la de ésta, ya que en su labor brinda una visión muy similar a la de la madre.

Las fortalezas que mencionan las maestras, tanto en su labor profesional como en su rol materno, son cualidades socialmente asignadas y contrapuestas a las masculinas, satisfaciendo el esquema patriarcal: buenas cuando satisfacen los deseos de los otros, y malas cuando no lo hacen.

Así, la escuela se convierte en un espacio cultural que refuerza y valora las características de las personas dependiendo del sexo. Transmitiendo y solidificando las inequidades de género, estas condiciones influyen decisivamente en la autovaloración de las niñas y los niños, en las opciones y actitudes que van asumiendo y que se reflejan en su vida futura.

Palabras clave: MATERNALIZACIÓN/ EDUCACIÓN/ GÉNERO/

Abstract: This is a qualitative study. The primary objective was to analyze the mother-like teaching roll in the classroom. The data was collected and analyzed using phenomenology hermeneutic and gender perspective methods. The subjects analyzed were the classroom, the teachers and the students.

It was evident that in their work, teachers adopt a prolongation of the maternal attitude. The children's perception is similar, since they receive a teachers' image that resembles their own mothers.

According to the teachers, their professional and maternal strengths are both socially assigned. Those qualities are also opposed to those related to the male gender, and fit within the patriarchal social scheme: women are good when they accomplish other people's needs and wishes, and they are bad if they don't.

Thus, the school is a cultural environment that defines and reinforces people's characteristics according to their gender. Those conditions transfer and promote gender inequalities, and have a great influence on the children's self-perception and attitudes, which are going to be adopted and expressed in their future life.

Key words: EDUCATION/ GENDER/ MATERNALITATION/

\footnotetext{
1 Psicóloga y Psicopedagoga. Magister en Psicopedagogía Licenciada en Enfermería. Licda en Psicología, todos los títulos de la Universidad de Costa Rica Profesora en la Escuela de Enfermería en el área de pediatría, de la Universidad de Costa Rica.
}

Correo electrónico: viriaml@yahoo.es

Artículo recibido: 15 de noviembre, 2004 Aprobado: 21 de febrero, 2005 


\section{1- Introducción}

La cuestión de los estudios de género en el campo de la educación abre un abanico muy amplio de posibilidades. No se restringe al ámbito de la educación formal, sino que incluye también la socialización de género, en la cual no se puede descuidar el papel que tiene la familia en la formación de los diferentes roles sexuales, el tipo de juguetes que se separa por sexo, el regañar a los niños si utilizan muñecas, el forzar a las niñas a hacer determinadas actividades que, inclusive en términos físicos, van formando cuerpos distintos (por ejemplo, matricular a las niñas en clases de ballet). Se trata de una socialización más amplia, que va de la casa a la escuela y viceversa, casi siempre de una manera muy consistente en términos de los modelos que se manejan en ambos espacios.

Hay una coincidencia en el uso de los estereotipos, en la reproducción de los roles en las prácticas marcadas por el sistema de género, que resulta muy armónico y que, en la práctica social, se asume de una manera aparentemente muy "natural". La socialización de género que se da en las familias convencionales también se reproduce de una manera muy "natural" en la escuela, y es apoyada por los materiales didácticos y por los roles de los maestros (Foucault, 1992).

La prolongación materna en el ámbito escolar ha sido estudiada por Elizondo (1993), quien presenta a las mujeres subordinadas doblemente y atrapadas en su propia identidad de género, ya que existe una tendencia institucional a insistir en un único modelo de mujer, y que quienes se adscriben a esta profesión la asumen como tal. En relación con lo anterior, Mannen (1998) desarrolló la importancia del tacto pedagógico, que parte no solo de tocar a los niños, sino de poseer casi una sensibilidad intuitiva y un sexto sentido sobre lo que las niñas y los niños requieren.

En un estudio de 1997, Luévanos partió de que los sujetos, las instituciones y las sociedades promueven, asumen, reproducen, o transforman, los procesos y los productores sociales, específicamente en este caso los que se refieren a la construcción de la identidad de género y a las relaciones entre ellos.

En un estudio en educación preescolar, Elizondo también encontró una doble maternidad que viven las mujeres que desempeñan la profesión de educadoras.

En Costa Rica, al igual que en otros países, la discusión sobre género se ha venido dando con más fuerza durante los últimos años; se encuentran innumerables estudios en diferentes áreas, por lo que se pretende contribuir con el presente estudio a la comprensión más global, de lo que se vive en el ámbito escolar en la cotidianeidad. Por lo tanto, se 
plantea como problema el siguiente: ¿Cuáles son las implicaciones de la extensión del rol materno de las docentes de la enseñanza básica dentro del aula?

\section{2- Referente Teórico}

Dentro de la información más relevante encontrada se debe mencionar la historia de género y educación, dentro de la cual la educación costarricense ha estado estructurada por la ideología patriarcal, que ha permeado los proyectos políticos y económicos en los distintos momentos históricos del país. La rigidez de la división del trabajo, que posiciona a las mujeres en la esfera privada, y a los hombres en la pública, y la segmentación de "carreras femeninas y masculinas", persisten como mitos en la imagen colectiva. Sin embargo, esa percepción está cambiando lentamente.

El otro aspecto a tomar en cuenta es la socialización como construcción subjetiva; según la sociedad, así es el ser humano, y, según el ser humano, así es la sociedad, en una relación que no es mecánica, lineal, ni unidireccional, sino dialéctica, por lo que la realidad objetiva (social) y subjetiva (psicológica "individuo"), no puede estudiarse aisladamente (Pérez, 1990). Es así, como la escuela es uno de los escenarios donde se da el adiestramiento en la sociedad de clases. Un complejo aparato ideológico provoca, y al mismo tiempo oculta, tal estado de limitación al desarrollo y lo privilegio y mayor estímulo para algunos, de manera que las exigencias sociales se transforman en necesidades y deseos individuales, para proporcionar gratificación y seguridad psicológica a la persona, y para asegurar la reproducción de las condiciones sociales (Facio 1992).

Por lo tanto, la cultura y el género están íntimamente relacionadas en la forma en que se instituye la diferencia cultural de la socialización de las niñas y los niños, permitiendo, de una manera imperceptible y oculta, favorecer la apropiación de patrones de identidad y de comportamientos permitidos y seguros según el sexo de las personas, y preparando, al ofrecer distintas, y a la vez determinadas herramientas, para la asunción de lugares predeterminados en la estructura social (Luévanos 1997).

De esa manera, los estereotipos sexuales y su transmisión dentro del aula se dan de acuerdo a la identidad genérica; cada persona se proyecta como un ser femenino o masculino, portador de determinados valores, actitudes, sentimientos, criterios y modos de actuación en función de su identidad genérica.

Según Lagarde (1994), en la identidad de género se está hablando de una cualidad histórica construida no sólo para las mujeres, sino también para los hombres, que tiene una correspondencia con la clase, edad, lugar que la mujer ocupa en el mundo; pero que hace 
referencia directa a la identidad asignada (cultural y socialmente) y a la autoidentidad (autoconciencia). De tal manera, como apunta Krauskof, "las identificaciones son procesos mentales automáticos e inconscientes por medio de los cuales un individuo llega a parecerse a otra persona en uno o varios aspectos al incorporar esas características". (2000, p. 40)

\section{3- Marco Metodológico}

Sustentado en lo anterior, es importante mencionar brevemente el marco metodológico que se dio en la investigación, que fue un estudio de tipo cualitativo, cuyo objetivo fue analizar la maternalización del rol docente en el aula. Se realizó una investigación inductiva, con un diseño flexible, que permitió analizar e interpretar los hechos, reconstruyendo los significados que las personas le atribuyen a sus acciones.

Dentro de esa perspectiva, y en vista de que la investigación se relacionaba con el campo educativo, el método que se utilizó para la recolección de los datos y su respectivo análisis e interpretación fue la fenomenología hermenéutica, en la cual, según Colás, Buendía y Hernández "los objetivos y temática de investigación se centran en el significado de la experiencia humana (fenomenología) y la comprensión de las acciones en el contexto (hermenéutica)" (1998, p.233). El método empleado requirió vincular los hechos sociales con fenómenos generales que se presentan a nivel societal, que nos construye como seres para la maternidad, y donde lo escolar está teñido de la cultura de la sociedad a la cual pertenece; es así como el aula se constituye en una unidad micro, donde lo social se presenta estructurado de una manera particular. Bajo esta posición epistemológica, los objetivos son descubrir temas o enfoques que se manifiestan como ilustraciones o percepciones que tienen los sujetos del mundo y, a través de ellos, establecer patrones interpretativos.

Es también importante resaltar que la perspectiva de género constituyó el eje central que orientó el proceso investigativo. Esta perspectiva o enfoque utiliza la categoría de género para "...comprender y explicar las relaciones de desigualdad, dominación y discriminación que existen entre los hombres y las mujeres" (Salazar, 1997, p.20), como producto de construcciones histórico- culturales, pero que pueden ser susceptibles a transformaciones.

Se definieron como unidades de análisis o sujetos de interés para la investigación a la maestra y a sus estudiantes. La docente, como el agente más importante de transmisión cultural, además de impartir las materias académicas, transmite mensajes verbales o no verbales, implícitos o explícitos, de manera consciente o inconsciente, permeados de sus propios valores, creencias y actitudes. Las estudiantes y los estudiantes, razón de ser de la 
educación escolar y motivo de existencia del docente, se constituyeron en la población meta del proceso de enseñanza y aprendizaje, siendo receptores de la influencia y de los mensajes de la docente y, por lo tanto, agente fundamental dentro de la interacción y la dinámica cotidiana del aula.

La escogencia para la observación dentro del aula de las niñas y los niños, así como de la maestra, se fundamentó en estudios realizados por Piaget y Köhlberg (1989), los cuales demostraron que tanto el aprendizaje como la maduración desempeñan un papel significativo en el desarrollo de su percepción, y que a la edad de 9 años se ha alcanzado cierto grado de maduración cognitiva y psicomotriz, por lo que es capaz de expresar en forma grafica y escrita sus sentimientos y percepciones.

El centro educativo estudiado se encuentra ubicado en el distrito de Orosi, cantón de Paraíso, provincia de Cartago.

La misión fundamental del centro educativo en estudio es brindar una oferta curricular y educativa que permita a las alumnas y alumnos desarrollarse en el plano individual, comunal y social. La población estudiantil está distribuida en diferentes niveles, desde preescolar hasta sexto año de primaria (cuadro 1).

\section{CUADRO 1}

\section{Matrícula en el Centro Educativo seleccionado durante el curso lectivo 2001 (por niveles)}

\begin{tabular}{lc}
\hline \multicolumn{1}{c}{ Nivel } & Total \\
\hline Preescolar & 10 \\
Primero & 7 \\
Segundo & 7 \\
Tercero & 15 \\
Cuarto & 7 \\
Quinto & 12 \\
Sexto & 9 \\
Total & 68 \\
\hline
\end{tabular}

Fuente: Leiva V. Implicaciones de la extensión del rol materno de las docentes de la enseñanza básica. S.E.P. UNED

Por las características de la modalidad bilingüe, se cuenta con un número igual de docentes para español e inglés, (cuadro 2), además de las correspondientes a las materias especiales (cómputo, formación espiritual, música, educación física y natación). 


\section{Cuadro No 2 \\ Personal que labora en la escuela \\ Seleccionada, según sexo, 2001}

\begin{tabular}{|l|c|c|c|}
\hline \multicolumn{1}{|c|}{ Tipo de cargo } & Mujeres & Hombres & Total \\
\hline Docente área de español & 4 & & 4 \\
Docente área de inglés & 4 & & 4 \\
Docente de asignaturas especiales & 3 & 1 & 4 \\
Docente administrativo & 2 & & 2 \\
Administrativo y de servicio & 2 & & 2 \\
Total general & 15 & 1 & 16 \\
\hline
\end{tabular}

Fuente: Leiva V. Implicaciones de la extensión del rol materno de las docentes de la enseñanza básica. S.E.P. UNED

Las categorías de análisis que se establecieron partieron de un aspecto básico que hay que concretar, y este fue el rol materno, que en las sociedades patriarcales se explicita en oficios maternos. Estos oficios maternos son aprendidos desde el nacimiento y llevan a muchas mujeres a realizarlos, no solo en la esfera privada, sino también en la esfera pública, en profesiones que están asociadas a actividades propias de la maternidad, tales como educación, enfermería, psicología, orientación, etc. De esa manera, a estas profesiones se les asigna actividades como educar, disciplinar asociado al castigo, enseñar a ser hombres y mujeres (dependencia e independencia; de lo público o lo privado, etc.), a las mujeres a cuidar de otros (alimentación, ropa, salud, dinero, desvalidos, etc.) antes que aprender a cuidarse a sí misma porque "cuando se trata de nosotras mismas siempre hay un sistemático no puedo, no quiero, no me atrevo; la impotencia es un producto del miedo" (Lagarde,1994, p. 21), canalizando la impotencia aprendida a través de la queja, la protesta constante y el depósito de la autoridad en otra persona (la madre, el padre o la dirección de la escuela) que en última instancia reproducen el sistema patriarcal. Como lo apunta Londoño (1992), "la interiorización de los estereotipos de género por vía de la socialización adquieren por la fuerza de la cultura, de la repetición, el carácter de lo obvio, de lo lógico y de lo natural" (Londoño, 1992, p.3).

Dentro de los instrumentos de exploración predilectos de la metodología cualitativa se encuentran la observación y la entrevista (Taylor \& Bogan, 1986; Rosetti, 1988; Barrantes, 1999). En congruencia con lo anterior, para la recolección de los datos se utilizaron las siguientes técnicas:

1. Observación directa, sistemática y permanente de la docente y de la vida cotidiana en el aula seleccionada.

2. Diario de campo 
3. Entrevista a las niñas, a los niños y a las maestras

4. Aplicación de test de frases incompletas y dibujo libre: Se realizó en varias sesiones de llenado de dos pruebas de frases incompletas, elaboradas por la investigadora con los títulos de "Mi escuela, mi maestra y yo", y "Mi casa, mi mamá y yo", con el fin de explorar la interiorización de las niñas y niños de la labor de la docente asociada al rol materno. Para complementar la información, se trabajó con las niñas y los niños para que ellos elaboraran un dibujo que les sugiriera, de la forma más clara, lo que para ellos significa el ser maestra y ser mamá. Estos dibujos sirvieron de insumos para abordar la temática de la maternalización de la enseñanza.

5. Unido a lo anterior, se realizaron sesiones de trabajo con todas las maestras de la institución sobre el significado del ser madre y docente, y también se trabajó con la elaboración de una metáfora sobre lo que para ellas significaba la disciplina en una niña o un niño.

6. Triangulación: la entrevista, la aplicación de los tests de frases incompletas, el trabajo desarrollado con las maestras, así como la observación no participante como complemento de los datos obtenidos, permitió la triangulación de los datos (Taylor \& Bogan,1992).

El análisis cualitativo de los datos requirió un cuidadoso examen de los aspectos de semántica, dinámica de grupo, comunicación no verbal, y fue una excelente experiencia de aprendizaje, ya que proporcionó percepciones sobre el pensamiento de las niñas y los niños. Los datos se analizaron, como se mencionó, bajo una perspectiva fenomenológica, y fueron interpretados con base en los elementos conceptuales aportados por la teoría de género, que se define como "aquella que utiliza la diferencia entre sexo y género como una herramienta heurística central' (González, 1994, p.12).

En el proceso de análisis e interpretación de los datos obtenidos se utilizó lo que proponen Taylor y Bodgan (1992): se realizó una lectura repetida de cada crónica, se indagaron los temas emergentes, se elaboraron esquemas de clasificación, describiendo e interpretando las categorías de análisis, que se mencionan abajo. Concomitantemente se fue elaborando el marco referencial para conocer la dimensión teórica de cada categoría y poder comprender mejor la realidad, así como cuadros de resumen, sus respectivas interpretaciones y conclusiones del tema en estudio. 
Se establecieron las siguientes categorías de análisis, que no pretendieron ser exhaustivas sino tan solo orientadoras; asimismo, se caracterizan en que están interrelacionadas entre sí. Estas son desarrolladas en el apartado de resultados:

Percepción que tiene las maestras como docente y como madre.

$>$ Comparación de la percepción afectiva de las niñas y los niños hacia su maestra y su madre.

$>$ Comparación de la percepción de las niñas y niños del rol que desempeñan las maestras y las madres.

$>$ Correspondencia entre expresiones verbales y no verbales, de la maestra hacia las niñas y los niños.

$>$ Comparación de la percepción de las niñas y niños de la maestra y de la madre como figura de autoridad.

$>$ Comparación de estereotipos de orden productor y corrector.

\section{4- Resultados}

A continuación se ofrece algunas de las características sociodemográficas de las personas participantes.

\begin{tabular}{l} 
Cuadro 3 \\
$\begin{array}{c}\text { Características de las maestras del Centro Educativo } \\
\text { según edad, sexo, estado civil e hijos }\end{array}$ \\
\begin{tabular}{|c|c|c|c|}
\hline Edad & Sexo & Estado civil & Hijos (as) \\
\hline $\begin{array}{c}\text { Oscilan entre los } \\
20 \text { a } 36 \text { años }\end{array}$ & $\begin{array}{c}\text { Todas son } \\
\text { mujeres }\end{array}$ & $\begin{array}{c}\text { Casadas } 2 \\
\text { Solteras } 7\end{array}$ & $\begin{array}{c}\text { Dos tienen } \\
\text { hijos, uno cada } \\
\text { una }\end{array}$ \\
\hline
\end{tabular} \\
\hline
\end{tabular}

Como puede observarse en el cuadro tres, las maestras que participaron en la investigación se encontraban en la edad adolescencia tardía y adultez joven, etapa importante desde la perspectiva que se analiza en la consolidación de la identidad de género y, por consiguiente, la reproducción de los roles adscritos a éste. Como lo menciona Pessoa:

Uno de los elementos más importantes en la construcción de la identidad de género es la condición de género, cuyas principales diferencias se definen a partir de la comparación y contraposición que hacen las y los jóvenes con respecto al otro sexo. (2000, p.30). 
El aula está integrada por 8 niños y 7 niñas. La mayoría de ellas y ellos procedían de distritos cercanos a la escuela. Once de las niñas y niños proceden de familias nucleares, entendidas como aquellas en las cuales ninguna otra persona, aparte del padre, la madre y los hermanos, convive con la familia bajo su mismo techo. Una niña vive sola con su madre, ya que sus padres están divorciados.

Es interesante analizar los cambios en los patrones económicos, mencionados en el cuadro 4.

\section{Cuadro 4}

Características de los sujetos participantes, según la persona que asume roles dentro del núcleo familiar

\begin{tabular}{|c|c|c|c|c|}
\hline $\begin{array}{c}\text { Trabaja alguno de } \\
\text { los padres }\end{array}$ & $\begin{array}{c}\text { Quién cuida al } \\
\text { niño(a) en la } \\
\text { casa }\end{array}$ & $\begin{array}{c}\text { Quién ayuda en las } \\
\text { labores escolares }\end{array}$ & $\begin{array}{c}\text { Cuando está } \\
\text { enfermo(a), lo } \\
\text { cuida }\end{array}$ & $\begin{array}{c}\text { Quién lo } \\
\text { castiga }\end{array}$ \\
\hline Sólo la madre: 0 & Madre: 9 & Madre: 9 & Madre: 8 & Madre: 7 \\
Sólo el padre: 2 & Padre: 0 & Padre: 1 & Padre: 0 & Padre: 3 \\
Ambos: 12 & Abuela: 3 & Ambos: 3 & Ambos: 5 & Ambos: 3 \\
Ninguno:1 & Otro: 3 & Hermano(a): 1 & Abuela: 1 & Nadie: 2 \\
& & Otro: 1 & Otro: 1 & \\
\hline
\end{tabular}

Fuente: Leiva V. Implicaciones de la extensión del rol materno de las docentes de la enseñanza básica. S.E.P. UNED

En la mayoría de casos trabajan ambos padres, pero se evidencia que, a pesar de la incursión de la mujer en el campo laboral, no hay cambio en los papeles tradicionalmente atribuidos a las mujeres, como son los de cuidado, enseñanza y corrección, pues éstos los sigue ejerciendo mayoritariamente una figura femenina, ya sea la madre, la abuela o una hermana. Esto es importante, ya que en el proceso de socialización primaria a través de la familia se establece la identidad de género, con los estereotipos, mitos y creencias que lleva consigo, y la cultura transmite a las niñas y los niños diversos rasgos que caracterizan el comportamiento masculino y el femenino. De esa manera, las niñas y los niños aprenden por modelaje que, aún cuando la madre trabaja, sigue siendo esta, u otra figura femenina, la que continúa asumiendo las tareas antes mencionadas.

Así, la familia en primera instancia a través de la madre y el padre, interviene en la socialización del ser humano desde el nacimiento, y continúa este proceso a través de la interacción de las niñas y los niños con el resto de la familia, luego con sus compañeras, compañeros, familiares, maestras y maestros (Lagarde, 1994).

La escuela constituye claramente un agente socializador explícito. Al entrar a la escuela las niñas y los niños tienen más contacto con otras niñas y niños, por lo que comienza a aparecer el interés por las actividades extrafamiliares; el socializarse es una de 
las principales tareas del desarrollo durante el período escolar (Van der Hoeven, 1997). Es interesante por ejemplo, la retroalimentación que recibían las niñas y los niños de su grupo de pares, cuando estaban llenando la ficha sobre la que se extrajo la información anterior. Los niños comentaban, "es feo ser niña, ya que son muy débiles", "las mujeres siempre lloran y juegan con muñecas, en cambio nosotros somos más fuertes"; los comentarios llegaron al punto que un niño pidió la ficha para cambiar la información, de manera que sus respuestas coincidieran con lo que los otros niños comentaban.

Se presentan a continuación los resultados obtenidos en cada una de las categorías de análisis.

\subsection{Percepción que las maestras tienen de su rol como docentes.}

Al realizar el trabajo con las maestras se encontró que su rol está asociado de una manera directa con las funciones de la maternidad, socialmente reconocida, de dominio del ámbito doméstico, como es el cuidar, educar, mantener el orden, la armonía, el cuidado de otros, y en esa interacción hay transmisión de valores, modelos de autocuidado y de autoresponsabilidad, necesarios para el desarrollo del las niñas y los niños.

Es evidente, como se muestra en el siguiente cuadro resumen, que las maestras han asumido lo que culturalmente se les ha delegado, como función adscrita a las mujeres, entendiéndola como ligada al instinto, explicándola como una función integrada a la naturaleza biológica de la mujer, llevando la idea implícita de que no se necesita esfuerzo para ejercerla, ni se requiere de un aprendizaje para cumplirla adecuadamente. Estos postulados coinciden con lo expuesto por Lagarde (1994), Luévanos (1997) y Palencia (1997), sobre cómo las características asignadas a la mujer social y culturalmente son asumidas por esta como atributos asociados al instinto.

Cuando a las maestras se les solicitó que explicaran lo que para ellas significaba ser madre y ser maestra, expresaron lo que se anota, de manera resumida, en cuadro 5.

\section{Cuadro 5}

Resumen de la comparación de opiniones de las maestras, según significado del ser maestra y de la maternidad, 2001

\footnotetext{
¿Qué significa ser maestra?
a Aquella persona que logra introducirse tanto en el cerebro de un niño (a), como en su corazón.
}

Es protección, crear vida, guiar al niño(a) por su paso por la vida, una gran dosis de amor y paciencia ya que entre ser maestro y ser padre las diferencias son meramente biológicas. 
a Representa muchas cosas: ser amiga, a Maternidad significa amor, responsabilidad, compañera, guía. Son muchos roles que hay entrega total.

que desempeñar, pero lo más bonito es ser una amiga.

Es ser como la segunda madre. Más que una profesión es VOCACIÓN.

a La maternidad es la más grande bendición que podemos recibir de Dios como mujeres.

a Una serie de responsabilidades, pero primero el enseñar y orientar en diversos aspectos como valores morales y hábitos, y ayudar en algún problema personal que tengan.

a Implica también mucha responsabilidad. La relación en este caso, quizás es más afectiva, precisamente por el vínculo. Una madre siempre educa, enseña. Una madre comparte muchas experiencias agradables y desagradables con sus hijos. Es siempre una amiga que intenta ayudar a sus hijos.

as aquella persona que le va a inculcar a los niños valores, actitudes y aptitudes, para desarrollar en ellos personas de bien, que ellos vean en nosotras una segunda madre.

Ser maestra es muy difícil; debemos tener siempre paciencia, estar alegres y cuidarnos en cómo nos expresamos.

a Significa para mí una responsabilidad muy grande de enseñar y guiar a los niños(as) para que en un futuro puedan ser personas capaces de salir adelante por sus propios medios.

También significa ser una segunda madre dentro del aula.

a Significa: educar, acompañar, guiar, dar, recibir. Significa amor, respeto, solidaridad y responsabilidad.

a Significa guiar, enseñar a desarrollarse como personas a los niños en todas las áreas (emocional, intelectual, social, etc).

a Para mí es una responsabilidad muy grande. En mis manos, está un niño indefenso, que aprenderá y se educará de acuerdo a los valores y costumbres que yo le inculque. Yo estoy muy feliz de ser madre, mi hija es mi mayor tesoro, es mi vida y por ella hago lo que sea.

a La maternidad es una responsabilidad muy seria que se debe asumir, dentro del matrimonio, cuando ambas partes estén completamente preparadas para afrontarla

a Implica muchas cosas, desde el hecho de ser amiga hasta llegar a ser el confidente del niño.

El compartir cada día con personitas que se están formando como personas es una bendición de Dios.

Fuente: Leiva V. Implicaciones de la extensión del rol materno de las docentes de la enseñanza básica. S.E.P. UNED

En síntesis, la percepción que ellas poseen sobre lo que es una mujer o la maternidad opera también como un organizador en sus vidas, implicando un comportamiento femenino en su labor como docente. Hay una coincidencia en el manejo del concepto de lo que es ser maestra y lo que es la maternidad, en términos de un estereotipo reproductor de los roles, que en la práctica social resulta armónico, y que es asumido de una manera aparentemente 
natural. Si las maestras son reproductoras de esos estereotipos sociales, se vislumbra la imposibilidad de poder modificar y construir otras maneras de convivencia entre los sexos mientras no se de una autorreflexión de su propia visión de mundo. Esto coincide con lo encontrado por Arauz (1997), quien apunta que la retroalimentación que reciben los y las estudiantes en el aula de clase, por su carácter directo, personalizado y repetitivo, constituye un factor determinante en el rendimiento académico y en la transmisión de estereotipos sociales.

Así, las maestras, como lo apunta Baró (1985), reproducen y son producto de las relaciones sociales objetivas del sistema dominante (patriarcal), ayudando a determinar la subjetividad de las personas acorde con las exigencias del sistema social dominante y mediante la transmisión de patrones culturales.

Las maestras asumen la maternidad, ligada culturalmente al instinto, como una función integrada a la naturaleza biológica de la mujer, de manera que las mujeres están destinadas al cuidado de las hijas e hijos, propios o ajenos, y la docencia es considerada como una extensión de la vida doméstica, en donde ella puede seguir desarrollando o manifestando el sentimiento femenino materno, por medio del amor maternal (Lagarde 1994; Batres, 1997).

En las manifestaciones de las maestras resulto claro que la identidad de género se incorpora y se manifiesta en las situaciones cotidianas familiares y escolares, tareas asignadas y asumidas donde sobresalen para la mujer las relacionadas con el cuidado de las niñas y los niños; esta construcción de género, impregnada de creencias, conflictos, contradicciones y deseos, está dado por una parte por su pasado familiar impregnado de estereotipos tradicionales respecto al género, y por otra parte, por los movimientos ideológicos y sociales a favor de la reivindicación de la mujer.

Resulta significativo que las fortalezas que mencionan las maestras, tanto en su labor profesional como en su papel como madres, están impregnadas de cualidades socialmente asignadas, como son paciencia, ternura, conciliación, amor, honestidad, cariño, darse a otros, mostrarse siempre feliz y contenta, con capacidad para brindar soporte emocional y fomentar la comunicación, y que son contrapuestas a las tradicionalmente masculinas.

La educación es concebida como una misión divina, que se desarrolla en el mundo de la inocencia, correspondiéndole a la maestra la categoría de "Ángel de la Guarda". Como ente de Dios, sirve para cumplir los designios de éste en la tierra, y por eso son mensajeras, guías, protectoras de las criaturas indefensas de la creación, como son los niños (Elizondo, 1993; Palencia, 1997). 
Además hay una concepción de lo que es niño o niña, percibido por ellas de una manera muy clara, reflejando una concepción de niña y niño como objeto, y no un sujeto del quehacer docente, codificada en una verticalidad, en donde se hace una negación de las posibilidades de las niñas y los niños de ser personas, y en cambio se les cataloga como objetos en vías de ser personas: "Ser maestra significa, el guiar, enseñar a desarrollarse como personas". Bajo esa perspectiva, la niña o el niño es algo que debe ser llenado, en su cerebro con conocimientos e información, y en su corazón con sentimientos, esperanzas, sueños, valores, etc.; son sujetos que llegan sin nada y que deben ser creadas a través de la educación formal.

\subsection{Comparación de la percepción afectiva de las niñas y los niños hacia su maestra y su madre.}

La percepción afectiva es definida como las manifestaciones de afecto sentidas hacia la maestra y la madre en términos de cariño y cuidados que prodigan estas hacia las niñas y los niños.

Hay coincidencia entre la percepción que tiene la maestra de su rol y la que poseen las niñas y los niños hacia ella, pues al asumir su labor dentro del aula, les brinda una visión muy similar a la de la madre, como puede observarse en el cuadro 6.

\section{Cuadro 6}

Comparación en la percepción afectiva de las niñas y los niños hacia su maestra y madre

\begin{tabular}{|l|l|}
\hline \multicolumn{1}{|c|}{ Madre } & \multicolumn{1}{c|}{ Maestra } \\
\hline Nos quiere & Nos ayuda \\
Nos cuida & Es buena \\
Limpia mucho & Nos enseña muchas cosas \\
Nos enseña a portarnos bien & Nos enseña todo \\
A ser buenos niños & La niña me cuida \\
Hace la comida & Me mira como si fuera su hijo \\
A educarnos & Nos regaña \\
A leer & Nos protege \\
\hline \multicolumn{1}{|c|}{ Fuente: Leiva V. Implicaciones de la extensión del rol materno de las docentes de }
\end{tabular}
la enseñanza básica. S.E.P. UNED

Este afecto está asociado a las funciones que se le asigna a la dimensión materna en el ámbito escolar. Las niñas y los niños perciben y han interiorizado a la figura materna con atributos de soporte emocional, asociados culturalmente a la mujer. Además, coincide con lo que las docentes consideran lo que debe ser la función de la maestra. Desde esta 
percepción afectiva se puede visualizar el aprendizaje que poseen las niñas y los niños sobre aspectos o etiquetamientos que identifican socialmente lo femenino, opuesto diametralmente de lo masculino, como es evidente en el cuadro 7.

\section{Cuadro 7}

Presentación de respuesta de las niñas y los niños, según el significado de ser mujer o ser hombre

\begin{tabular}{|c|c|}
\hline Te gusta ser mujer porque & Te gusta ser hombre porque \\
\hline $\begin{array}{l}>\text { Porque le ayudo a mi mamá } \\
\text { Porque juego con muñecas, } \\
\text { soy bonita, me encantan las } \\
\text { flores y no me gustan los } \\
\text { muñecos feos. } \\
>\text { Porque es bonito jugar de } \\
\text { barbies } \\
>\text { Porque juega mamá mucho. } \\
>\text { Porque somos más } \\
\text { coquetas. } \\
>\text { Porque quiero ser feliz. } \\
>\text { Porque soy ordenada. }\end{array}$ & $\begin{array}{l}>\text { Porque puedo jugar libre y } \\
\text { no tengo que jugar } \\
\text { muñecas. } \\
\text { P Porque puedo jugar bola. } \\
>\text { Puedo jugar bola y soy } \\
\text { fuerte. } \\
>\text { Porque soy fuerte. } \\
>\text { Porque soy fuerte, juego } \\
\text { bola y más } \\
>\text { Porque puedo jugar bola. } \\
>\text { Puedo hacer muchas } \\
\text { cosas. }\end{array}$ \\
\hline
\end{tabular}

Fuente: Leiva V. Implicaciones de la extensión del rol materno de las docentes de

la enseñanza básica. S.E.P. UNED

Se puedo observar que las niñas y los niños poseen ya una clara idea socialmente constituida de los modos de comportamiento particulares de los papeles femenino y masculino, tendientes a resguardar la dicotomía hombre (espacio público), mujer (espacio privado) de la cultura.

La mujer debe ser, según las niñas, "buena, quieta, bonita, coqueta", cuyo fin es aprender a ser madres y a cuidar a otros. En contraposición, para los niños el hombre debe ser del afuera, "jugar libre, fuerte", poco sensible, entre otros. Esto, unido a los mensajes que envían las maestras, y posiblemente las madres, sobre la maternidad y la enseñanza, hacen que la escuela y el hogar se constituyan realmente en un medios de reproducción y no de corrección de estereotipos, ya que es muy difícil modificar algo que se ha interiorizado y arraigado dentro de cada uno de nosotros desde tan temprana edad.

\subsection{Comparación de la percepción de las niñas y los niños del rol que desempeñan las maestras y las madres.}

Asociado a la categoría anterior, las niñas y los niños perciben a sus maestras y a sus madres con atributos socialmente establecidos como naturales o sobrenaturales, la limpieza (para purificar el mundo), encargarse de cuidar a otros sean los hijos propios o los de otros, 
además de cultivar a las niñas y los niños que se encuentran a su cuidado. Esto es sumamente importante, ya que para las niñas y los niños, las maestras deberían ser: "más buenas, más cariñosas, felices, buenísimas, respetuosas, responsables" y las mamás deberían ser: "buenas, muy felices, excelentes, bonitas, muy cuidadosas".

Esto evidencia el influjo social, sobre lo que debe ser una madre o su maestra en la extensión del rol maternal dentro del aula, poniendo de manifiesto la influencia de la escuela y la familia en el aprendizaje de los papeles genéricos idealizados del ser madre y el ser maestra -maternidad colectiva- como principios regulativos de lo que significa ser mujer y ser hombre en la sociedad; por eso Mead (1972) establece que la escuela es una instancia secundaria de socialización que recrea y refuerza lo aprendido en la familia.

Las funciones maternas están asociadas a estructuras de manejo disciplinario que han aprendido las mujeres para la corrección y el control de la disciplina en las niñas y los niños. Por tanto, asumen una posesión de las niñas y los niños, sienten que tienen el deber de corregir y formar a esos seres "indefensos" que son las niñas y los niños, y se puede caer en una sociedad de culpa y castigo, con la fatal creencia de que educar es castigar, que el castigo es un método para disciplinar, y entonces las madres, y las maestras, o "segundas madres", pueden canalizar parte de sus rabias a través del "castigo educativo" (Apple,1994; González, 1994; Lagarde, 1994; Batres 1997; Gómez,1997). Como lo menciona Lagarde, "en nuestra sociedad gran parte de la afectividad femenina es construida en torno a la culpa; la culpa se convierte en una cualidad de género" (Lagarde, 1992, p.16). A manera de ejemplo de lo hasta aquí mencionado, cabe presentar el cuadro 8, donde se resume lo manifestado por las maestras acerca de educar y disciplinar a un niño.

\section{Cuadro No. 8}

Presentación de metáforas de las maestras, según el significado de lo que es: educar y disciplina

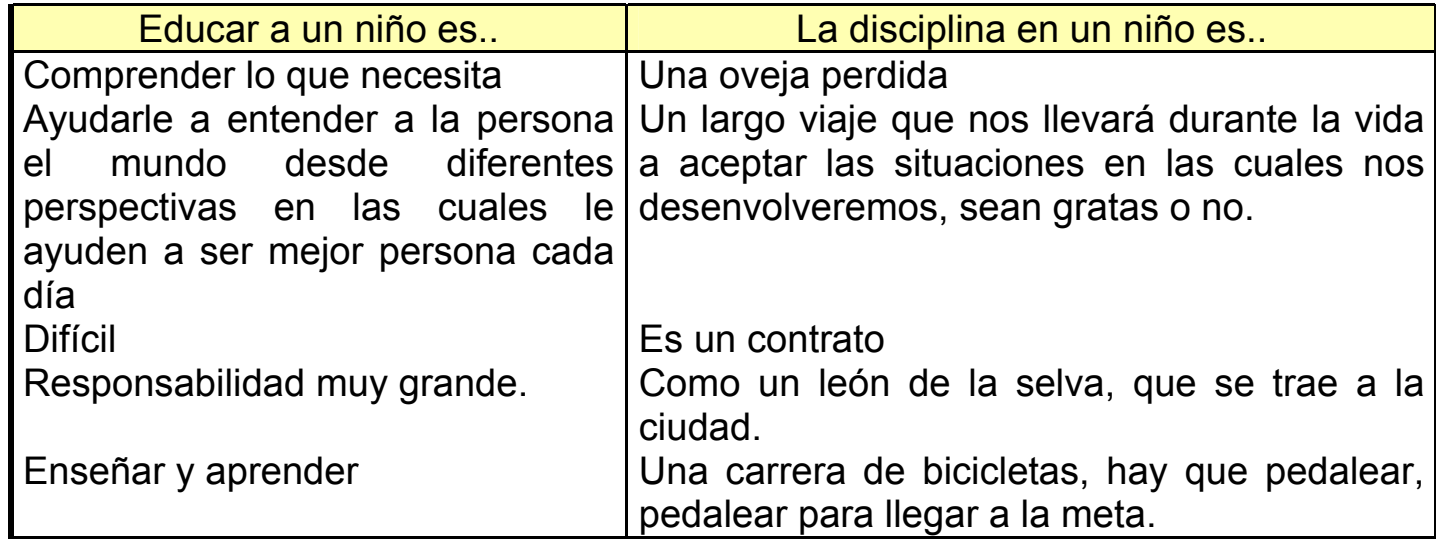




\begin{tabular}{|l|l|}
\hline $\begin{array}{l}\text { Linda pero, ardua tarea } \\
\text { Es perseverancia, paciencia } \\
\text { amor }\end{array}$ & $\begin{array}{l}\text { Es la mezcla entre el saber y aprender. } \\
\text { Es una balanza entre el amor por lo que se } \\
\text { hace y exigencia para entregar el máximo. } \\
\text { La disciplina es un nivel de constructor, que } \\
\text { debe estar siempre la gota en el medio. }\end{array}$ \\
\hline
\end{tabular}

Fuente: Leiva V. Implicaciones de la extensión del rol materno de las docentes de

la enseñanza básica. S.E.P. UNED

Dentro de las metáforas que establecieron las maestras, se percibe una posición de total dependencia e indefensión de las niñas y los niños, donde ellas poseen el poder de cuidar, guiar, proteger y ser el mensajero social y divinamente seleccionado para salvar a los niños de sus propios impulsos.

Se establece una posición pasiva de las niñas y los niños, en donde las maestras poseedoras del saber tienen la capacidad de discriminar entre lo bueno y lo malo para los infantes, a pesar de sus sentimientos y pensamientos. A su vez, hay una valorización casi nula de los años vividos por las niñas y los niños, previos al ingreso escolar, pues es hasta cuando entran a la escuela que empieza su verdadera formación en hábitos, aptitudes y valores morales.

Cabe mencionar que a pesar de la imagen idealizada de esa madre-maestra buena, las niñas y los niños asocian la disciplina con estados de enojo permanente. Entonces, la realidad captada por las niñas y niños es la de una madre o maestra molesta, agobiada, brava, radicalmente opuesta al ideal materno de "madres y maestras felices, realizadas y gozosas".

La siguiente categoría de análisis se encuentra entrelazado a lo expuesto con anterioridad.

\subsection{Correspondencia entre la expresión verbal y no verbal.}

Por su relación con lo implícito y lo explícito, se encontró algo fundamental que se ha venido develando en el transcurso del presente artículo, y es lo que la maestra como tal ha manifestado explícitamente, lo que para ella es "ser maestra" y su asociación directa a la maternalización de su quehacer dentro del aula, y lo que las estudiantes y los estudiantes perciben a través de la mirada, no-solo de su maestra, sino también de su madre.

En referencia al tacto de la maestra con la mirada, las niñas y los niños lo asocian a una característica punitiva, como se puede observar en el cuadro 9. 


\begin{tabular}{|c|c|}
\hline \multicolumn{2}{|c|}{$\begin{array}{c}\text { Cuadro } 9 \\
\begin{array}{c}\text { Percepción de las niñas y los niños del tacto de la } \\
\text { maestra con la mirada }\end{array}\end{array}$} \\
\hline $\begin{array}{l}\text { Percepción de la mirada de la } \\
\text { maestra }\end{array}$ & $\begin{array}{c}\text { Percepción de la valorización de si } \\
\text { mismos a través de la mirada de la } \\
\text { maestra }\end{array}$ \\
\hline $\begin{array}{l}\text { Pienso que me regaña } \\
\text { No la miro } \\
\text { Me escondo } \\
\text { Está brava conmigo } \\
\text { Me asusta } \\
\text { Hago silencio } \\
\text { Pienso que está enojada } \\
\text { Me mira como si fuera una mosca } \\
\text { Me siento perro } \\
\text { Corro } \\
\text { Sonrío } \\
\text { Me siento feliz }\end{array}$ & $\begin{array}{l}\text { Perro } \\
\text { Loca } \\
\text { Malito } \\
\text { Travieso } \\
\text { Culpable } \\
\text { Monstruo } \\
\text { Gatito } \\
\text { Muñeca } \\
\text { Linda } \\
\text { Buena } \\
\text { Winnie the Pooh } \\
\text { Un estudiante }\end{array}$ \\
\hline
\end{tabular}

Todo esto, relacionado íntimamente a un papel asignado a la madre de corregir y educar a los infantes para que sean personas de "bien". La niña y el niño valora la mirada de la maestra y la equivale a la concepción que ella puede tener de ellas y ellos, que en general es de forma peyorativa; sólo tres niñas (ver cuadro anterior) consideraron la percepción de la maestra a través de la valoración de su mirada con características más positivas. Esto coincide con lo expuesto por Van Manen (1998), sobre el tacto pedagógico a través de la mirada y la importancia de que el mensaje que se envía a la niña y al niño en forma verbal sea coincidente con el mensaje que se da a través de la mirada, "puede que quiera elogiar a un niño difícil, que da guerra porque necesita llamar la atención y que se le anime. En ese caso puedo expresar palabras de apoyo correctas, pero mis ojos traicionan mi verdadero sentimiento de disgusto" (Van Manen, 1998, p.186).

Esto es interesante, pues las niñas y los niños refirieron que la maestra es buena, sabe mucho; sin embargo, la percepción a través de la mirada es interpretada por la niña y el niño con otro mensaje. Virginia Satir (1993) manifiesta que la niña y el niño se visualiza a sí misma y a sí mismo a través de lo que ve en la mirada de las personas significativas: se sienten amados si ven amor, se sienten respetados si ven respeto; pero serán desordenados si ven intolerancia, y se sentirán rechazados si ven en la mirada que no son tolerados. 
Lo anterior se relaciona con lo que las niñas y los niños refieren que se sentirían más felices si la maestra en el área socio afectiva "felicita", "me quiere", "se acuerda de mí", "fuera buena", "me mirara como a su bebé", y en el área académica "explicara", "me ayudara", "nos dejara salir". Además, es importante mencionar que las niñas y los niños asumen que la felicidad de la maestra es comparativamente igual a la de su mamá. Está, por lo tanto, asociada directamente a comportamientos de índole disciplinarios y académicos, de tal manera que las niñas y los niños asumen un falso poder para hacer feliz o infeliz a su madre o maestra con sus comportamientos. Un ejemplo de esto es la respuesta de las niñas y los niños sobre lo que hace feliz a la maestra: "trabajamos", "hacemos silencio", "nos portamos bien", "escribimos rápido". Y en relación con la mamá se puede encontrar expresiones coincidentes: "me porto bien", "hago algo bueno", "hago cosas sin que me las diga", "no peleo", "estoy contenta", "soy bueno", "saco buenas notas".

La siguiente categoría de análisis se encuentra interrelacionada con lo anteriormente expuesto.

\subsection{Comparación de la percepción de las niñas y los niños de la maestra y la madre como figuras de autoridad.}

Desde la Sociología y la Psicología educativa, se sabe que la actitud de los docentes y las docentes hacia las estudiantes y los estudiantes, así como el modelo que representan las figuras de autoridad dentro de las escuelas, resultan ser algunos de los mecanismos para transmitir y reforzar los papeles y estereotipos genéricos en el ámbito escolar.

Esta categoría de análisis se contrapone y a la vez refuerza, la visión mística de la mujer que ejerce la maternidad o que maternaliza su quehacer, como una representación de Dios, que se mencionaba en el análisis de la primera categoría. Esta imagen de un Ser Todopoderoso que da la vida, la educa, la forma, la construye, es una figura fantástica que las niñas y los niños internalizan. Esto concuerda con la respuesta de los niños sobre que la mayor parte de las madres son "buenas, bonitas, corazón, amor, cariñosas, felicidad, que nos alimentan"; luego, cuando se dan cuenta que la madre no es todo lo que ellas y ellos pensaban, que no atiende a todo, que ese ser todopoderoso es débil, "aprenden que esa madre es inferior y al mismo tiempo superior, por el hecho de ser adulta...pero cuando la observa en relación con otros, la vive igual de carenciada, sometida e impotente que él mismo" (Lagarde,1992,p.13), es maltratada y golpeada; al ir internalizando nuevos valores, los niños descubren que su madre es vulnerable, y eso les genera mucho miedo. Ese es, quizá, el período en el cual se encuentra el grupo de niñas y niños estudiados, al referir que 
no les gusta las mamás que: "pegan, enojan, pelean, regañan, son muy bravas, son malas, no aman".

Así mismo, la figura materna, fomentada por la actuación de la maestra, proyecta la imagen fantástica de la buena madre: amor, cercanía y gozo. Pero también es todopoderosa, y castigadora, y es representada por las niñas y los niños como la madre mala, manifestando, entre otras cosas, que no les agrada la maestra que posee aspectos inherentes a actos agresivos como gritos, regaños, enojo, o que se asocia a exigencias académicas. Muchos de las maestras y los maestros, como lo menciona Van Manen, "no tienen conciencia de que están dedicando buena parte de la jornada al mantenimiento de unas normas de funcionamiento y a ciertas maneras de hacer, cuya eficacia y necesidad, por lo demás, no siempre han sido probadas" (Van Manen, 1998, p.87). Este comportamiento es aceptado por la niña y el niño como normal, pero con una expectativa de cambio en el fondo.

La maestra parece satisfacer el esquema patriarcal: son buenas cuando satisfacen los deseos de los otros, y son malas cuando no lo hacen. Este es, más o menos, el esquema de lo materno, que es seguido por la educadora en su constante contacto con las niñas y los niños.

\subsection{Comparación de los estereotipos de orden productor y corrector.}

Es importante aclarar que desde la psicología social, se define a los estereotipos de orden productor como aquellos tendientes a reproducir el sistema social dominante, mientras que los de orden corrector son los que tratan de generar emancipación y que tienden a mejorar la igualdad en la relaciones intergenéricas y de poder social. Así, con base en el trabajo realizado con las niñas, los niños, las docentes y las observaciones dentro del aula, se puede mencionar que la identidad genérica que traen consigo las niñas y los niños desde sus familias de origen es reforzada en la escuela desde el orden productor de estereotipos. Estas creencias parten desde lo subliminal, ya que no se evidencian dentro del discurso oficial, revestido por un espíritu de igualdad, que, como hemos visto hasta aquí, no es real.

El proceso de identificación y desidentificación que viven las niñas y los niños en su diario contacto social con sus grupos de pares, y la relación con sus maestras, más el reforzamiento social, ya sea por los medios de comunicación masiva o en el interior de la familia, facilita que se vaya interiorizando en la persona el género, conformándose la identidad más arcaica de género (reproductora) y no la emancipadora (correctora). 
En definitiva, junto con la familia, la escuela es el segundo círculo concéntrico socializador intencional, y el que comparte con ella esa responsabilidad en la transmisión de patrones de género.

A pesar de que todas las maestras entrevistadas consideran fuera de orden hablar de conductas sexistas dentro de la escuela, y que los prejuicios y características que lo configuran van siendo menos habituales en nuestra sociedad, esto no es congruente con sus concepciones sobre lo que significa ser maestra, donde se perfila claramente lo que por generaciones se ha asignado a la mujer como natural, y que es, en definitiva, un constructo social: la maternidad.

Al preguntarles por las similitudes entre una maestra y una madre, las niñas y los niños refirieron atributos asociados a la maternidad; la única diferencia, se refirió al contacto físico, "pues la mamá sí puede pegar y la maestra no". Además los niños refirieron que la maestra es más afectiva con las niñas, que las protegen más, mientras que debe estar pendiente de los niños, y "tenerlos bajo control".

Todos estos estereotipos reproductores, se enfrentan a algunos correctivos, que se muestran débiles, como es el exaltar atributos asociados con la capacidad de trabajo, inteligencia, esfuerzo, búsqueda de mejoras económicas, persona a la que se puede imitar, sin importa su sexo.

Así, la escuela se convierte en un espacio cultural que refuerza y valora las características de las personas dependiendo del sexo al cual pertenecen. Los mecanismos encubiertos, por medio de las cuales se transmiten y se solidifican las inequidades de género, influyen decisivamente en la autovaloración de las niñas y los niños y en las opciones y actitudes que van asumiendo a lo largo de su educación y en los resultados finales que se reflejan en su vida futura.

Todas las categorías analizadas arrogaron reflexiones importantes que pueden resumirse en el siguiente apartado.

\section{Breves consideraciones y recomendaciones finales}

1. Existe congruencia, tanto de las maestras como de las estudiantes y los estudiantes, en la percepción del ámbito escolar como una prolongación materna, en donde las maestras deben, como requisito, poseer actitudes y características que las identifiquen con el rol materno.

2. Particularmente se demuestra en este estudio que las maestras asumen su función como algo asociado directamente a la maternidad, desde una imagen idealizada, 
concebida como la misión divina, de protección, guía, corrección, formación, a las criaturas indefensas que son las niñas y los niños, aun de sus propios deseos.

3. A pesar de que las maestras están conscientes de los estereotipos que se manejan sobre género, es evidente que ellas los han interiorizado dentro de su discurso, por lo que es fácil pensar que en el vínculo que se establece con las niñas y los niños se da una transmisión de estereotipos del orden reproductor, más que los del orden corrector, de tal forma que se refuerza y proyecta las expectativas en lo que se refiere a maternidad y al rol de la maestra.

4. La formación de valores y formas de comportamiento socialmente aceptados es una función asignada a la maternidad, y es asumida por las mujeres dentro de un vínculo de poder horizontal, en donde las medidas agresivas físicas y verbales permitidas en el orden social establecido, y que tienen que ver con el orden privado, se manifiestan en la percepción que poseen las niñas y los niños de su madre y de su maestra.

5. Se considera también que en el ámbito universitario se maneja un currículo oculto, similar al estudiado dentro de las escuelas de primaria, que comprende un conjunto de normas, valores y creencias relativas a la función de la mujer, no afirmadas de forma explícita, que son transmitidas a las estudiantes y los estudiantes por medio del contenido formal y de las relaciones de la vida escolar y del aula de clase.

6. Se pone de manifiesto la presencia de estructuras asimétricas de poder: de un lado está la maestra, que representa la institución y el saber, poseedora de toda la autoridad, y por el otro está la niña y el niño, que no sabe nada, que se encuentra en la posición de sumisión, que no pone en duda la autoridad de la maestra y de la que depende que realice los cambios esperados.

7. La relación entre el educador y el educando debería ser de guía del primero hacia el segundo, permitiendo el desarrollo de la autonomía, la unicidad y la independencia de la niña y el niño, de tal manera que pueda desarrollar su capacidad de resolver problemas académicos y de la vida cotidiana, sin una dependencia del docente en su toma de decisiones, haciendo al niño más activo. La niña o el niño debe saber que la educadora o el educador está ahí para facilitar el proceso integral y no para dar a la niña y al niño lo que debe aprender en forma predeterminada sino en un proceso individual e integral.

8. Es fundamental que los centros formadores de educadores y educadoras fomenten, dentro de la práctica pedagógica, la simpatía sincera de parte de la maestra y el maestro hacia los alumnos, y no la maternalización de su quehacer. La simpatía que 
establezca con las alumnas y los alumnos le permitirá desarrollar, y no dar por sentado o "innato", la capacidad de detectar estados de ánimo y de humor. La voz, la mirada y los gestos del educador permiten una relación más íntima con el educando, que no sería importante si no fuera unido con la reflexión sobre la acción pedagógica, lo que permite pensar, tomar decisiones $\mathrm{y}$, de alguna manera, liberar el quehacer pedagógico.

9. Mientras no se de una autorreflexión de su propia visión de mundo, las maestras seguirán siendo reproductoras, en su relación con las niñas y los niños, de los estereotipos sociales. Es por esto, que el Ministerio de Educación, debe realizar talleres para las maestras y los maestros, cuyo objetivo sea promover la autorreflexión anticipadora, de manera que se posibilite el establecimiento de probables alternativas activas o interactivas (reflexión acción), que se dan cuando se presenta una situación determinada y que hay que enfrentar inmediatamente; esta capacidad puede ser desarrollada dentro de su formación en los centros universitarios, para luego ponerlo en práctica en su diario quehacer.

10. Se requiere introducir dentro de las ofertas curriculares de los centros educativos, el eje transversal de género y de derechos humanos, que promueva la reflexión del quehacer docente, tanto en la formación de recurso humano, como en la propia labor docente universitaria.

\section{Referencias}

Apple, M. (1994). Educación y poder. España: Editorial Paidos.

Arauz Ramos, S. (1997). Efectos del género en los patrones de retroalimentación en el aula: estudio observacional de las niñas y los niñosde IV y $\mathbf{V}$ grados de una escuela pública. San José: Tesis Magíster Scientiae, Posgrado en Psicología, Universidad de Costa Rica.

Barrantes, Rodrigo. (1999). Investigación: un camino al conocimiento. Un enfoque cualitativo y cuantitativo. San José: EUNED.

Baró, M. (1987). Tres tesis sobre la socialización. Memorias Seminario 4 y 5 octubre. Heredia: Departamento de Psicología. Universidad Nacional.

Batres, G. (1997) Del ultraje a la esperanza: tratamiento de las secuelas del incesto. San José: ILANUT.

Centro Nacional para el Desarrollo de la Mujer y la Familia. (1997) Descubriendo mi socialización de género. Módulo 1. San José: El Centro. 
Centro Nacional para el desarrollo de la mujer y la familia. (1997) Los compromisos de Beijing y su cumplimiento en Costa Rica. San José: El Centro.

Colas, P.; Buendía, L. y Hernández, P. (1998) Métodos de Investigación en Psicopedagogía. Madrid: McGraw- Hill.

Elizondo, A. (1993). El maternaje en educación preescolar: un modelo de mujer._Tesis doctoral en Educación, Barcelona: Universidad de Barcelona.

Facio, A. (1992). Cuando el género suena cambios trae: Metodología para el análisis de género del fenómeno legal. San José: ILANUD, Proyecto Mujer y Justicia Penal.

Foucault, M. (1992). Microfísica del poder. España: Ediciones la Piqueta.

Gómez, M.; Mir, V.; Serrats, M. (1997). Propuesta de intervención en el aula: técnicas para lograr un clima favorable en la clase. España: Narcea, S.A. de ediciones.

González, A.; Castellanos S.. (1994). "Estereotipos sexuales: masculinidad y feminidad en la edad escolar". Educación. (Segunda época) (82) mayo- agosto.

Instituto Nacional de las Mujeres. Centro Mujer y Familia (CFM), (1995). Diagnóstico acerca de la situación de las mujeres en Costa Rica: Informe del Gobierno de Costa Rica. San José: Instituto Nacional de las Mujeres.

Kraukof, D. (2000). Adolescencia y Educación. San José: Editorial EUNED.

Lagarde, M. (1992).Género y feminismo- desarrollo humano y democracia. Madrid: Horas y Horas.

Lagarde, M. (1994). Género e identidades. Ecuador: UNICEF, Programa Regional de Capacitación de la mujer para el Desarrollo.

Leiva, V. (2001). Implicaciones de la extensión del rol materno de las docentes de la enseñanza básico en la socialización y disciplina en el aula. Tesis Magíster. San José: UNED, Sistema de Estudios de Posgrado.

Londoño, A. (1992). Hacia la recuperación del asombro: la violencia contra la mujer, asunto de salud pública. Nicaragua: Memorias del Primer Seminario Subregional sobre Violencia contra la Mujer.

Luévanos, Aguirre, C. (1997). Identidad de género en los procesos socioculturales de la familia y la escuela. Historias de vida con padres y madres docentes de la educación primaria. Tesis doctoral en Sociología, Universidad de Guadalajara.

Mead, M. (1972). Educación y cultura. Buenos Aires: Paidós.

Moore, H. (1991). Antropología y feminismo. Madrid: Cátedra.

Peassoa, X. (2000).Cuaderno de Juventud \# 2. Juventud y Vida Cotidiana. Costa Rica: Editorial Izcandé, M.C.J.D. 
Pérez, R (1990). Carácter social y tendencias socio- políticas del burócrata costarricense: análisis de esta relación en burócratas estatales del área metropolitana en el contexto de las transformaciones del estado costarricense: Proyecto de tesis para optar por la licenciatura en Psicología. Escuela de Psicología. UCR

Piaget, J. (1989). La Construcción de lo Real en el Niño. España: Crítica.

Salas, C., J. (1996). La mentira en la construcción de la masculinidad. Revista Costarricense de Psicología, mayo № 12.

Satir, V. (1993). Conjoint Family Therapy. California: Ed. Science and Behavior.

Taylor, S. (1986).Introducción a los métodos cualitativos de investigación. Barcelona: Paidos.

Van der Hoven, R. y otros. (1997). Estrategias para el sistema de Educación Técnica en el proceso de formación e incorporación productiva de las mujeres adolescentes. San José: s.e.

Van Manen, M. (1998). El tacto en la enseñanza. El significado de la sensibilidad pedagógica. Barcelona: Paidós.

Vargas, M., L. (1996). La agresión y la violencia doméstica. Revista Costarricense de Psicología, mayo $\mathrm{N}^{\circ} 12$.

Zuñiga, I. (1996). La percepción idealizada de la maestra, su conocimiento y sabiduría en las relaciones interpersonales maestro-niño de una escuela pública del área metropolitana de San José. Imágenes, 3 (6), 59- 70

Zúñiga, I. (1997). Relación afectiva maestra-niño; autorealización y percepción acerca del grupo en el ámbito de las relaciones interpersonales en una escuela pública del área metropolitana de San José. Imágenes, 4 (7), 67- 77. 